\title{
Editorial
}

\section{Em foco: biomateriais na odontologia}

Há muito tempo cerâmicas e metais têm contribuído para a vida humana e têm sido utilizados em prótese dentária ${ }^{1}$. Desde o último século, materiais poliméricos mudaram radicalmente nosso estilo de vida e provocaram avanços no campo da odontologia preventiva. Agora, os dentistas usam uma enorme variedade de estruturas fundamentadas nestas três classes de materiais (cerâmica, metais e polímeros), considerando as suas propriedades individuais, funcionais e estruturadas na forma de compósitos. Naturalmente que o foco da atenção está nos biomateriais, que são materiais biologicamente compatíveis com o corpo huma$\mathrm{no}^{1}$, ou de acordo com o glossário de termos protéticos ${ }^{2}$ : qualquer substância que não um medicamento ou droga que pode ser usada por qualquer período de tempo, como parte de um sistema, para tratar, desenvolver, ou substituir qualquer tecido, órgão ou função do corpo. Muitos tipos diferentes de tecidos moles e duros são usados como biomateriais em odontologia. No entanto, a maioria desses materiais é estruturada para utilização permanente ou definitiva, ou seja, não émetabolizada. Assim, biomateriais biodegradáveis ou bioabsorvidos, de forma concomitante com o reparo biológico, são continuamente o foco de pesquisas que objetivam, especialmente, a reparação de defeitos ósseos e doenças periodontais.

Os compósitos estruturados (scaffolds) biocompatíveis, especialmente aqueles à base de cerâmicas, polímeros e cultivo celular, têm sido entusiasticamente estudados para uso em engenharia de tecidos com objetivos regenerativos e reparadores. Além disso, a compreensão de conceitos e eventos associados à embriologia e à biologia molecular deve auxiliar no desenvolvimento de biomateriais funcionais e biotecnologias com o objetivo de reparar, substituir ou produzir tecidos ou estruturas organizadas, tais como a polpa e o próprio dente. Assim, a cooperação científica entre várias áreas do conhecimento, em especial, dos biomateriais, da nanotecnologia, da biologia molecular e da engenharia de tecidos é fundamental para a inovação e o desenvolvimento da odontologia, ou qualquer biociência.

Essa edição especial da RFO-UPF é uma boa representação de estudos sobre biomateriais na odontologia, pois podemos aprender com sistemas rotatórios, terapia fotodinâmica e desinfecção química na endodontia, com o avanço tecnológico dos dessensibilizantes dentinários, com a reparação tecidual e enxertia óssea associada à implantodontia, com a bioatividade de metais, e com o uso de ionômeros de vidro e do tratamento restaurador atraumático na odontopediatria e saúde pública brasileira. Com isso, a comunidade científica da área odontológica demonstra o seu empenho no desenvolvimento e na aplicação dos biomateriais em procedimentos clínicos com benefício à população.

Prof. Dr. Alvaro Della Bona Editor da RFO-UPF

\section{Referências}

1. Della Bona A. Bonding to ceramics: scientific evidences for clinical dentistry. São Paulo: Artes Médicas; 2009.

2. The glossary of prosthodontic terms. J Prosthet Dent 2005, 94(1):10-92. 